\title{
Transfer of Pimelobacter tumescens to Terrabacter gen. nov. as Terrabacter tumescens comb. nov. and of Pimelobacter jensenii to Nocardioides as Nocardioides jensenii comb. nov.
}

\author{
M. D. COLLINS,${ }^{1} \mathrm{M}$. DORSCH ${ }^{2}$ AND E. STACKEBRANDT ${ }^{2 *}$ \\ Department of Microbiology, Agricultural Food Research Council, Institute of Food Research, Reading Laboratory, \\ Shinfield, Reading RG2 9AT, United Kingdom, ${ }^{1}$ and Institut für Allgemeine Mikrobiologie, \\ Christian-Albrechts-Universität, 2300 Kiel, Federal Republic of Germany ${ }^{2}$
}

\begin{abstract}
The phylogenetic interrelationship of members of the genera Nocardioides and Pimelobacter were examined by using reverse transcriptase sequencing of $16 \mathrm{~S}$ ribosomal ribonucleic acid. The sequence studies demonstrated that Nocardioides albus, Nocardioides luteus, Pimelobacter jensenii, and Pimelobacter simplex represent a coherent phylogenetic group at the genus level, whereas Pimelobacter tumescens occupies a separate line of descent. On the basis of sequence data and the chemotaxonomic distinctiveness of the latter organism, we propose that Pimelobacter tumescens be reclassified in a new genus, Terrabacter, as Terrabacter tumescens comb. nov.
\end{abstract}

Arthrobacter simplex and Arthrobacter tumescens are among the few named species of coryneform bacteria which contain cell wall peptidoglycans based on LL-2,6-diaminopimelic acid $(5,16)$. The two species thus differ in peptidoglycan composition from Arthrobacter globiformis, the type species of the genus, which contains lysine as the dibasic amino acid (16). Although there is now general agreement that these species should be removed from the genus Arthrobacter, their taxonomic position remains controversial (10). Suzuki and Komagata (19) proposed the creation of a new genus, Pimelobacter, to accommodate these species. A third species, Pimelobacter jensenii, was also proposed for an atypical $A$. simplex strain (19). However, there is evidence of considerable chemical heterogeneity within the genus Pimelobacter (3, 12, 19). Pimelobacter (Arthrobacter) simplex and $P$. jensenii are unusual among coryneform and related bacteria in producing complex mixtures of straightchain saturated, monounsaturated, and iso-, anteiso-, and 10 -methyl branched fatty acids $(3,12,19-21)$. However, Pimelobacter tumescens differs from these species in lacking 10 -methyl branched acids and in containing substantial levels (ca. 20\%) of monounsaturated terminally branched acids (3). $P$. simplex and $P$. jensenii also differ from $P$. tumescens in synthesizing 2-hydroxylated long-chain fatty acids $(3,12)$. The polar lipid compositions of these taxa are also quite different. $P$. simplex and $P$. jensenii possess diphosphatidylglycerol, phosphatidylglycerol, and hydroxyphosphatidylglycerol $(3,12,21)$. However, $P$. tumescens lacks hydroxyphosphatidylglycerol and in addition synthesizes two unknown aminophosphoglycolipids $(3,12)$. Such major differences in lipid composition between $P$. simplex and $P$. jensenii on the one hand and $P$. tumescens on the other hand indicate that these taxa should probably not be accommodated in the same genus. Interestingly, the lipid composition of $P$. simplex and $P$. jensenii is indistinguishable from that of members of the genus Nocardioides $(3,12)$. Indeed, primarily on the basis of similarity in lipid composition, O'Donnell et al. (12) proposed that $P$. simplex be transferred to the genus Nocardioides. However, $P$. simplex does not possess a nocardioform morphology (extended primary and aerial

\footnotetext{
* Corresponding author.
}

mycelium), and its placement within the genus Nocardioides has been questioned (14).

$16 \mathrm{~S}$ ribosomal ribonucleic acid (rRNA) cataloging shows that $P$. simplex is well removed from the arthrobacters sensu stricto and indicates that this species occupies a line of descent the branching point of which is as low as that of other major lines within the actinomycetes $(18,19)$. To date comparative sequencing studies with other members of Pimelobacter and Nocardioides have not been made. Therefore, in an attempt to clarify the relationship of $P$. simplex to the genus Nocardioides and to resolve the position of $P$. tumescens, we analyzed and compared long stretches of the $16 \mathrm{~S}$ rRNA primary structures of these taxa.

\section{MATERIALS AND METHODS}

Cultures and cultivation. Type strains Nocardioides albus DSM 43109, Nocardioides luteus NCIB 11455, P. jensenii DSM 20641, $P$. simplex NCIB 8929, and $P$. tumescens NCIB 8914 were grown in shake flasks (casein peptone, $10 \mathrm{~g}$; yeast extract, $5 \mathrm{~g}$; glucose, $5 \mathrm{~g} ; \mathrm{NaCl}, 5 \mathrm{~g}$; water, 1 liter; $\mathrm{pH} 7.4$ ) to late exponential phase at $25^{\circ} \mathrm{C}$.

Sequence determination and analysis. Crude ribonucleic acid was isolated as described previously (7). Reverse transcriptase sequencing of ribonucleic acid was achieved by using the method of Lane et al. (11). The sequence of oligonucleotide primers, their target sites, and the electrophoretic separation conditions used for complementary deoxyribonucleic acid have been described by Embley et al. (7). Some sequence ambiguities were resolved by using terminal transferase (6). Sequence data were aligned and homology values were determined with the Beckman Microgenie program (15). Calculation of evolutionary distance values $\left(K_{\text {nuc }}\right)$ and construction of phylogenetic trees followed previously published procedures $(8,9)$.

\section{RESULTS AND DISCUSSION}

The partial reverse transcriptase sequences of the five strains investigated are shown aligned in Fig. 1. The homology and derived $K_{\text {nuc }}$ values from 1,449 bases used for determining intragroup relationships are shown in Tables 1 


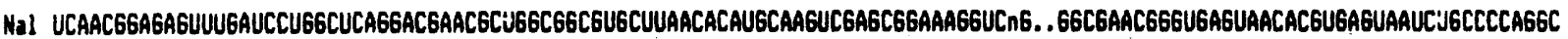

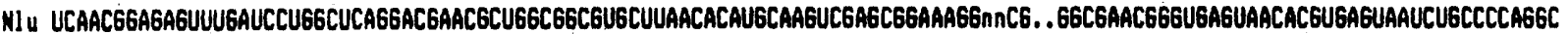

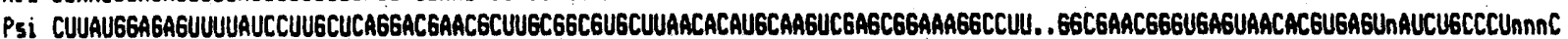

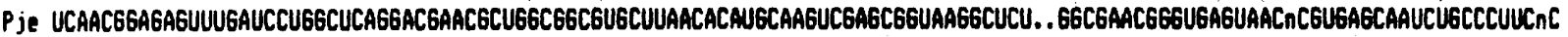

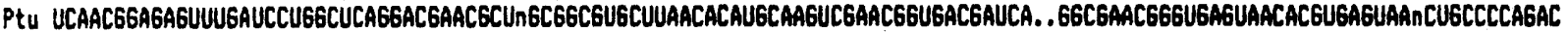

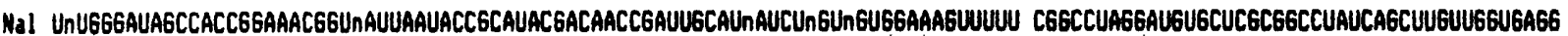

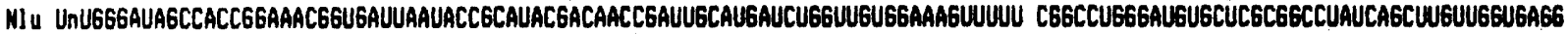

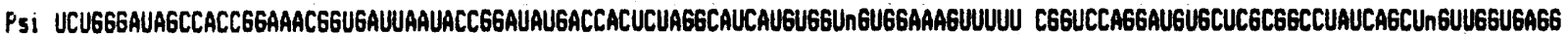

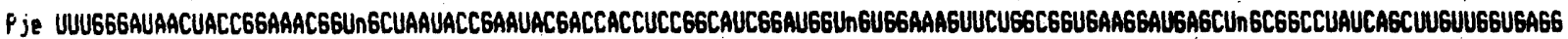

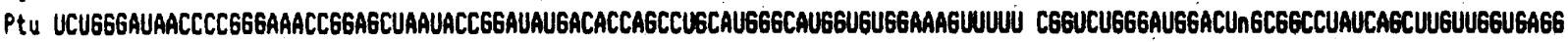

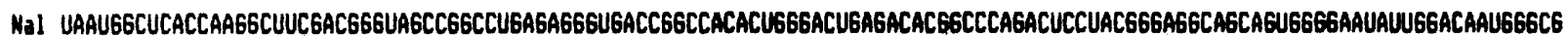

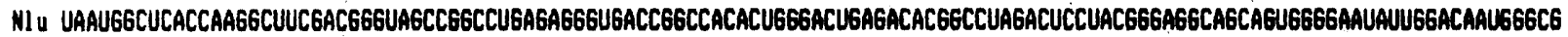

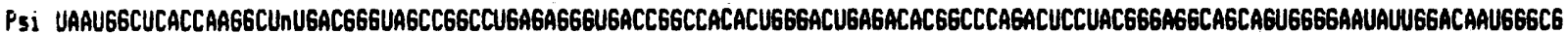

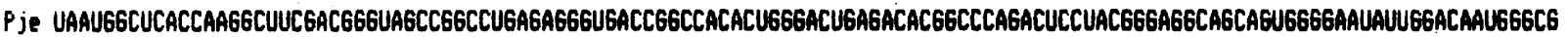

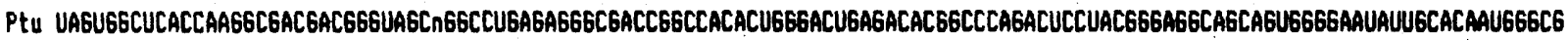

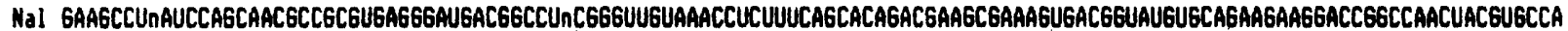

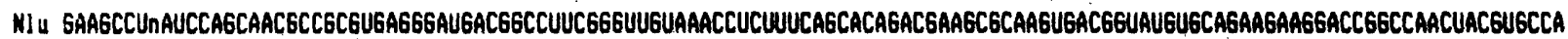

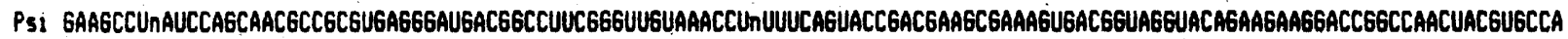

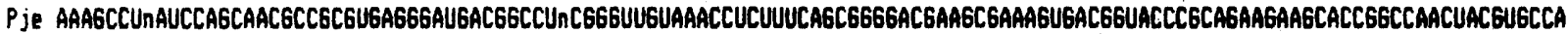

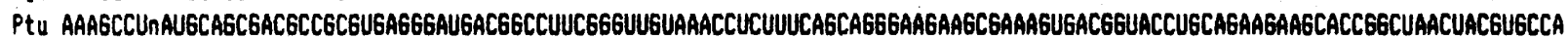

Nal GCAGCCGC6GUAAUACGUAG6GUCCUAGCCLUAUCCG6AAUUAUUG66CGUAAAG6GCUUGUAGGCnGUnUGUCGCGUCG6GAGUGAAAACCAGGUGCUUAACACCUnGCCUnCUUCCGA NIU GCAGCCGCGGUAAUACGUAG6GUCCUAGCCUUAUCCGGAAUUAUUGGGCGUAAAGGGCUUGUAGGC GUnUGUCGCGUCGGAnGUGAAAACCAGGUGCUUAACACCUnGCCUGCUUUCGA

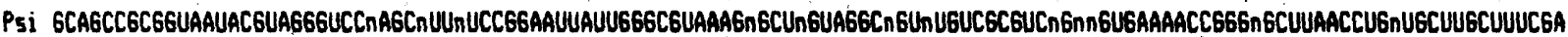

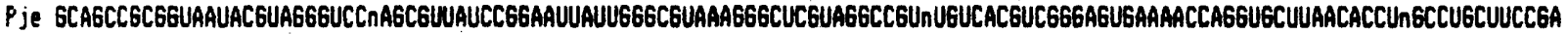
Ptu SCnGCCGCGGUAAUACGUAG6GUGCnAGCGUUGUCCGGAAUUAnUGGGCGUAAAGAGCUnGnAGGUGGUUnGUCGCGUCUGCUGUGAAAAUCCGAGGCUCAACCUC66ACUnGCnGUG6G

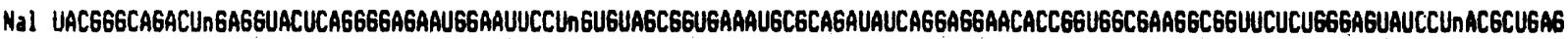

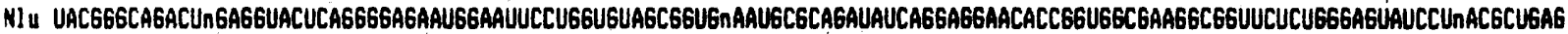

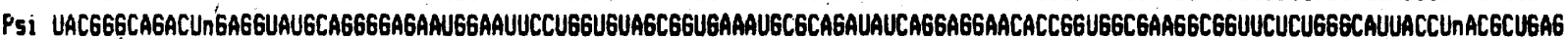

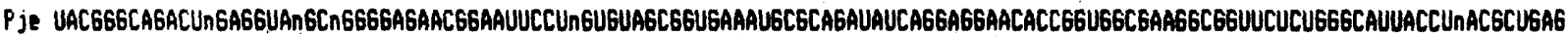

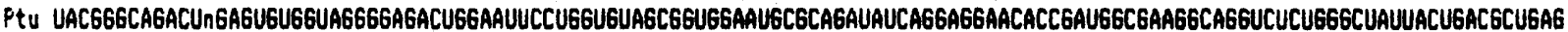

Nal GAGCGAAAGUGU6666AGCGAACA G6AUUAGAUACCCUGGUAGUCCACACCGUAAACGUUGG6CGCUAGGUGUG66ACACAUUCCACGUnUUCCGUGCCGCAGCUAACGCAUUAAGCGCC MIU GAGCGAAAGUGU6G6GAGCGAACAGGAUUAGGUACCCUG6UAGUCCACACCGUAAACGUU6G6CGCUAGGUGU66GAUCCAUUCCACGG UUCCGUGCCGCAGCUAACGCAUUAAGCGCC

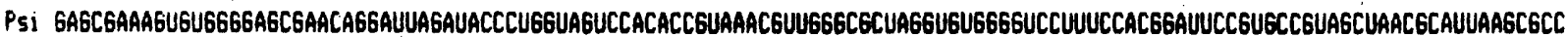

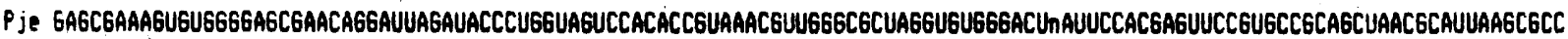
PtU AAGCGAAAGCAUGg6gagCGAACA GGAUUAGAUACCCUGgUAGUCCAUGCCGUAAACGUUG6gAACUAGgUGUGG6UCUnAUUCCnCGAGAUCCGUGCCGCAGCUAACGCAUUAAGUUCC

and 2. The phylogenetic tree derived from the latter values is depicted in Fig. 2. The two Nocardioides species which we examined possess very high sequence homology $(>98 \%) . P$. simplex and $P$. jensenii also share a relatively high level of homology (ca. 95\%) and are approximately equidistant from each other and Nocardioides species. P. tumescens displays significantly lower levels of homology to these species (ca. $90 \%$ ). To ascertain the intergroup relationships, the sequences of the species described above were compared with those of 18 previously studied actinomycetes from 14 genera (2, 4, 7; E. Stackebrandt, J. Smida, and M. D. Collins, J. Gen. Appl. Microbiol., in press; J. Smida, T. M. Embley, M. D. Collins, D. Hahn, and E. Stackebrandt, unpublished data). The latter comparison was based on 480 nucleotides involving only variable positions between points 200 and 1,435 (Escherichia coli numbering system [1]). Representative homology values are shown in Table 1 . The branching pattern (Fig. 3) indicates that all Nocardioides spp. and pimelobacters constitute a separate line of descent, comparable in phylogenetic depth to the depths of the major lines (i.e., Streptoverticillium, Frankia, Actinomyces, Propionibacterium, Pseudonocardia, Bifidobacterium, and mycolic acid-containing taxa). It is evident from both trees that $P$. tumescens is only loosely related to $P$. simplex, $P$. jensenii, $N$. albus, and $N$. luteus, forming an individual subline.

The high levels of sequence homology among $N$. albus, $N$. luteus, $P$.jensenii, and $P$. simplex are in accordance with the high degree of chemical similarity among these species (3, 12 ) and the results of phage typing (13). These data strongly support the union of Nocardioides and Pimelobacter into a single genus, for which Nocardioides has priority (by date of publication). The inclusion of $P$. simplex and $P$. jensenii in the genus Nocardioides makes the latter heterogeneous with respect to morphology. However, there is now evidence that morphological characters are not reliable indicators of relatedness $(17,18)$. The degree of morphological differences among these taxa is in any case debatable. Prauser (13) noted that strain IMET 7801, initially intended to be the type strain of $N$. albus, lost the ability to form aerial mycelium on 


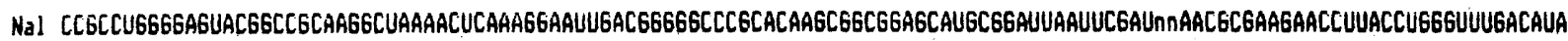

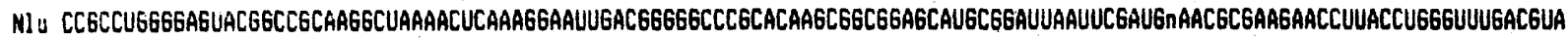

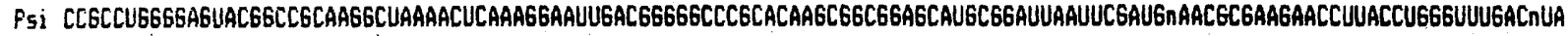

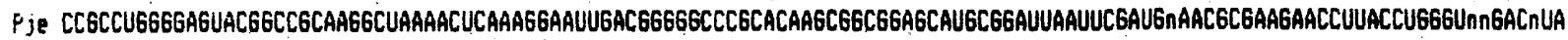

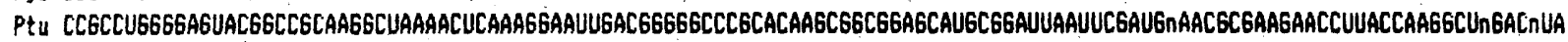

Na! CACCGgAAAGCCGUAGAGAUACG6CCCCUUUUAGUC GGUGUACAGGUGGUGCAUGGCUGUCGUCAGCUCGUGUCGUGAGAUGUUGGGUUAAGUCCCGCAACGAGCGCAACCCUCGUCC N1 CACCGGAAAGCUGCAGAGALGUAGCCCCUnUUnGUC GGUGUACAGGUGGUGCAUGGCUGUCGUCAGCUCGUGUCGUGAGAUGLUGGGUUAAGUCCCGCAACGAGCGCAACCCUCGUCC

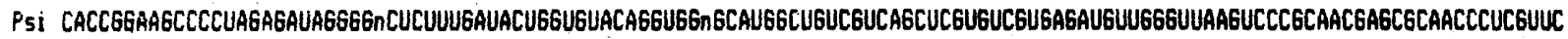
$P$ je UGCC6GAAAGCUCUAGAGAUAGAGCCCCUnUUnGUC GGUGUACA6GUGGUGCAUGGCUGUCGUCAGCUCGUGUCGUGAGAUGUUGGGUUAAGUCCCGCAACGAGCGCAACCCUnGUCU PtU CACCGGAAUCACUCAGAGAU G6GUnCGUCUUCGGACUG6UGUACAGGUGGUGCAUGGUnGUCGUCAGCUCGUGUCGUGAGAUGUUGGGUUAAGUCCCGCAACGAGCGCAACCCUCGUCC

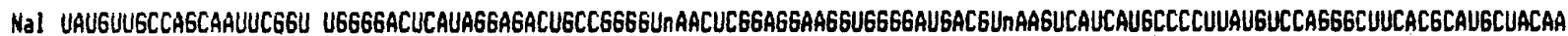
Ni] UAUGUUGCCAGCAAUUCGGU UGG6GACUCAUAGGAGACUGCCG66GUnAACUCGGAGGAAGGUGG6GAUGACGUnAAGUCAUCAUGCCCCUUAUGUCCAG6GCUUCACGCAUGCUACAA

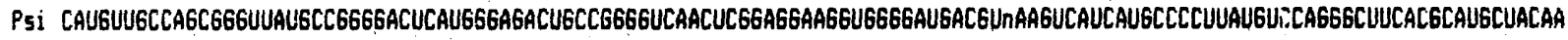
$P$ je UAUGUUGCCAGCACGUAAUGGUG66GACUCAUAAGAGACUGCCG66GUCAACUC66AG6AAGgUG66gAUGACEUnAAGUCAUCAUGCCCCUUAUGUCCAGG6CUUCACGCAUGCUACAA

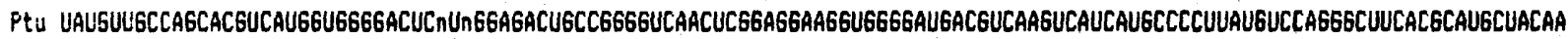

Na! U66CC6GUACnAAGG6CUGCGAUCCCGUnAG6GUGAGCGAAUCCCAAAAAGCCGGUCUCAGUUCG6AUUG66GUCUGCAACUCGACCCCAUGAAGULGGAGUCGCUAGUAAUCGCAGAUC N] U UGGCCGGUACnAAG6GCUGCGAUCCCGUGA6GGUGAGCGAAUCCCAAAAAGCCGGUCUCAGUUC6GAUUGGGGUCUGCAACUCGACCCCAUGAAGUCGGAGUCGCUAGUAAUCGCAGAUC

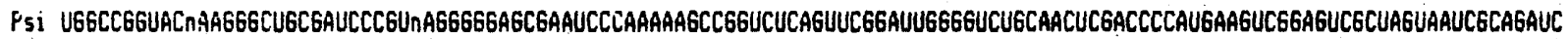

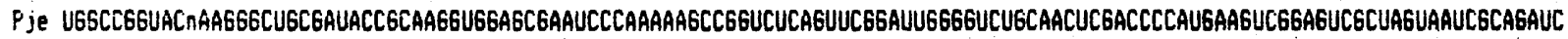
PtU UGgCCGgUACAAAGg6CUGCGAAACCGCGAGGUGGAGCGAAUCCCAAAAAACCGGUCUCAGUUCGGAUUG6GGUCUGCAACUCGACCCCAUGAAGULGGAGUCGCUAGUAAUCGCAGAUC

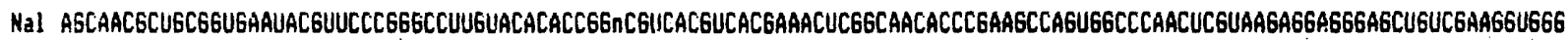
N] $U$ AGCAACGCUGCGGUGAAUACGUUCCC6GGCCUUGUACACACCGnnCGUCACGUCACGAAAGUCGGCAACACCCGAAGCCAGUGGCCCAACCCUUGU AGn6GAGCUGUnGAAGGUG6G

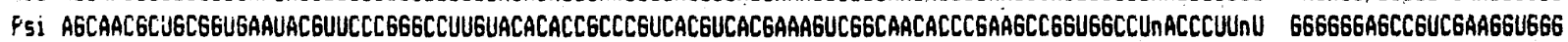

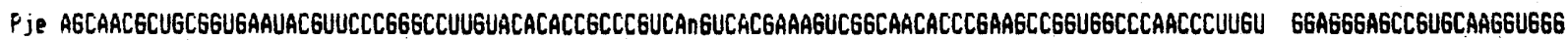
FtU AGCAACGCUGCGGUGAAUACGUUCCCG6GCCUUGUACACACCGCCCGUCAAGUCACGAAAGUCGGUAACACCCGAAGCC GGUGGCCCAACCCUUGU GGnGG6AGCCGUCGAAGGUGGG

\section{Nal GCUGGCGAU \\ N] G GCUGGCGAU \\ Psi gCUGGCGAU \\ Fye GCU66CGAL \\ Ptu ACUGGCGAU}

FIG. 1. Partial 16S rRNA sequences of N. albus (Nal), N. luteus (Nlu), P. jensenii (Pje), P. simplex (Psi), and P. tumescens (Ptu). The dots indicate an unsequenced region of 18 nucleotides. n, Undetermined nucleotide. A space indicates a nucleotide gap. The asterisk at the $5^{\prime}$ terminus corresponds to position 1 , and the last base at the $3^{\prime}$ terminus corresponds to position 1,497 of the $E$. coli sequence (1).

continued subculture. Furthermore, Nocardioides species exhibit a developmental cycle in which with increasing age the substrate mycelium fragments into irregular rod-shaped to coccoid elements, giving the appearance of coryneform morphology. Therefore, we consider the morphological objections insufficient grounds for retaining the separateness of these genera. We concur with the proposal of O'Donnell et al. (12) to reclassify $P$. simplex as Nocardioides simplex and also propose the new combination Nocardioides jensenii. The ribonucleic acid studies do not support the suggestion of Suzuki and Komagata (19) that $P$. tumescens, $P$. simplex, and $P$. jensenii should be included in the same genus. $P$. tumescens has been shown to be quite different from the latter two species (3). In view of the isolated phylogenetic position of $P$. tumescens, together with its chemical distinctiveness, we suggest that this organism be reclassified in a new genus, Terrabacter, as Terrabacter tumescens comb. nov.

Description of Nocardioides jensenii (Suzuki and Komagata) comb. nov. The description below is based on data from references 3 and 17 . A rod-coccus growth cycle occurs during growth on complex media. Exponential-phase cells are long, irregular rods (ca. 0.6 to 1.0 by 2.0 to $7.0 \mu \mathrm{m}$ ). Older cultures are composed of coccoid cells. Aerial myce-

TABLE 1. $K_{\text {nuc }}$ values for Nocardioides and Pimelobacter species

\begin{tabular}{lcccc}
\hline \multicolumn{1}{c}{ Strain ${ }^{a}$} & \multicolumn{2}{c}{$K_{\text {nuc }}$ value with: ${ }^{b}$} \\
\cline { 2 - 5 } & $\begin{array}{c}\text { Pimelobacter jensenii } \\
\text { DSM 29641 }\end{array}$ & $\begin{array}{c}\text { Pimelobacter tumescens } \\
\text { NCIB 8914 }\end{array}$ & $\begin{array}{c}\text { Nocardioides albus } \\
\text { DSM 43109 }\end{array}$ & $\begin{array}{c}\text { Nocardioides luteus } \\
\text { NCIB 11455 }^{\mathrm{T}}\end{array}$ \\
\hline Pimelobacter simplex NCIB 8929 & $0.122(0.091)$ & $0.214(0.101)$ & $0.112(0.059)$ & $0.107(0.058)$ \\
Pimelobacter jensenii DSM 29641 & & $0.201(0.087)$ & $0.093(0.057)$ & $0.117(0.054)$ \\
Pimelobacter tumescens NCIB 8914 & & $0.230(0.109)$ & $0.231(0.101)$ \\
Nocardioides albus DSM 43109 & & & $0.019(0.015)$ \\
\hline
\end{tabular}

${ }^{a}$ NCIB, National Collection of Industrial Bacteria; DSM, Deutsche Sammlung von Mikroorganismen.

${ }^{b}$ The values not in parentheses were calculated from 480 nucleotides. The values in parentheses were based on a comparison of 1,449 nucleotides. 


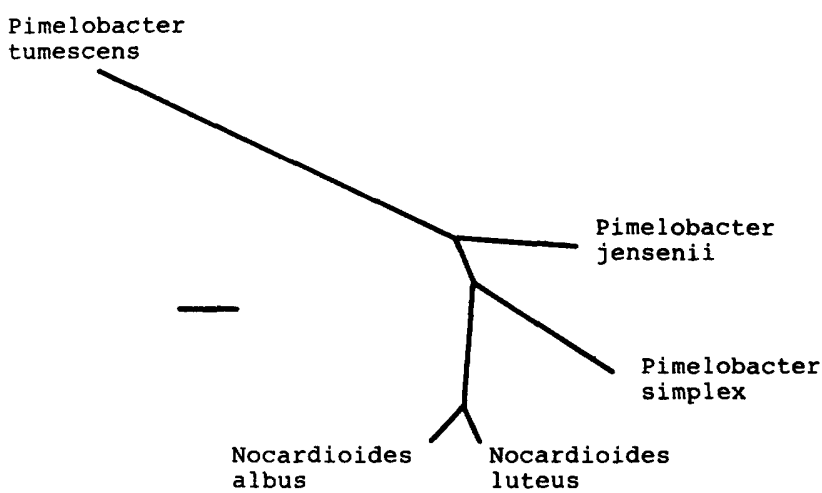

FIG. 2. Unrooted phylogenetic tree displaying the interrelationship of Nocardioides and Pimelobacter species. The branching pattern was derived from $K_{\text {nuc }}$ values (Table 1 ). Bar $=0.01 K_{\text {nuc }}$ unit.

lium is not formed. Nonmotile. Colonies are glossy, smooth, entire, and white. Growth in $5 \% \mathrm{NaCl}$ but not $10 \% \mathrm{NaCl}$. Does not grow at $37^{\circ} \mathrm{C}$. Catalase positive. Oxidase negative. Nutritionally nonexacting; growth occurs in suitable mineral salts medium with an ammonium salt or nitrate as the sole nitrogen source and glucose as the carbon-plus-energy source. Acid is not produced from glucose and other sugars in peptone-based media. A wide range of organic compounds are utilized as sole or principal carbon-plus-energy sources for growth, including glucose, sucrose, L-rhamnose, and acetate. Deoxyribonuclease is produced. Urease positive. Nitrate is reduced to nitrite. The cell wall peptidoglycan is based on LL-2,6-diaminopimelic acid (type LL- $\mathrm{A}_{2} \mathrm{pm}-\mathrm{Gly}_{3}$ ). The nonhydroxylated long-chain fatty acids are complex, consisting of straight-chain saturated, monounsaturated, and iso-, anteiso-, and 10-methyl-branched types; 2-hydroxy fatty acids are also produced. The polar lipids comprise diphosphatidylglycerol, phosphatidylglycerol, phosphatidylinositol, and hydroxyphosphatidylglycerol. The major isoprenoid quinone is MK-8 (II,III- $\left.\mathrm{H}_{4}\right)$. The guanine-pluscytosine content of the deoxyribonucleic acid is $68.8 \mathrm{~mol} \%$ (thermal denaturation method).

The type strain is strain NCIB 9770 (= JCM $1364=$ DSM 20641). The description of the type strain corresponds to that of the species.

Description of Terrabacter gen. nov. Terrabacter (Ter.ra. bac'ter. L. n. terra, earth; M. L. masc. n. bacter, masc. equivalent of Gr. neut. n. bacterum, a rod; Terrabacter, earth [soil] rod). The description below is based on data from references 3, 8, 10, and 17. A rod-coccus growth cycle occurs during growth in complex media. Irregular rods are observed in exponential-phase cultures; stationary-phase cultures are composed of mainly coccoid cells. Both rods and coccoid forms are gram positive. Cells are non-acid fast and do not form endospores. Rods are nonmotile or occasionally motile. Growth at 10 and $35^{\circ} \mathrm{C}$. Optimum temperature for growth, ca. 25 to $30^{\circ} \mathrm{C}$. Does not survive heating at $63^{\circ} \mathrm{C}$ for $30 \mathrm{~min}$. Growth in $5 \% \mathrm{NaCl}$. Catalase positive. Oxidase negative. Obligately aerobic. Acid is not produced from glucose and other sugars in peptone-based media. Cellulose is not hydrolyzed. Nitrate is reduced to nitrite. The cell wall peptidoglycan contains LL-2,6-diaminopimelic acid (variation $\mathrm{A} 3 \gamma$ ) as the diamino acid. Mycolic acids are absent. The long-chain cellular fatty acids are primarily of the iso-methyl branched types; straight-chain saturated, anteiso-methyl branched, and monounsaturated iso-methyl branched acids are also present. The polar lipids comprise diphosphatidylglycerol, phosphatidylethanolamine, phosphatidylinositol, and some unknown amino-containing phospho-

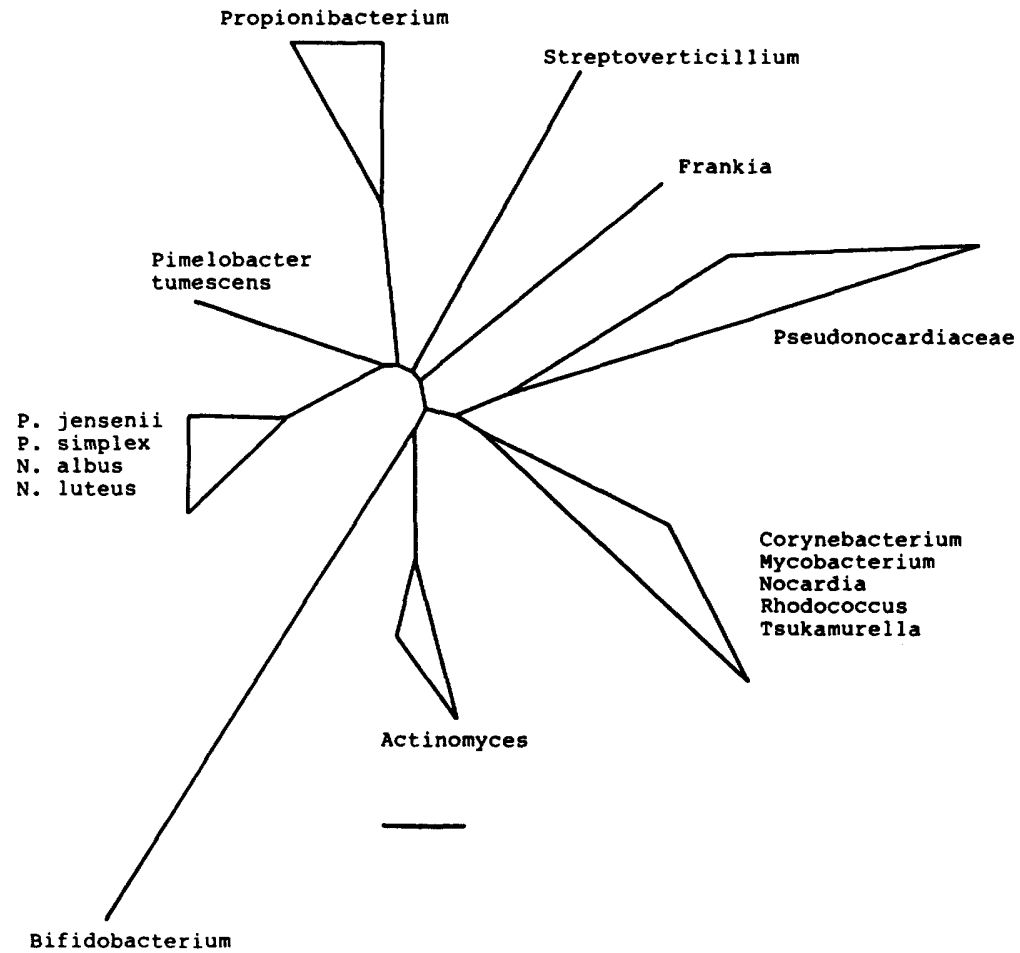

FIG. 3. Unrooted phylogenetic tree displaying the relationship of Nocardioides and Pimelobacter species to other reference actinomycetes. Bar $=0.04 K_{\text {nuc }}$ unit. 
TABLE 2. 16S rRNA sequence homologies for Nocardioides species, Pimelobacter species, and some reference actinomycetes $\%$ Homology with ${ }^{b}$ :

Strain

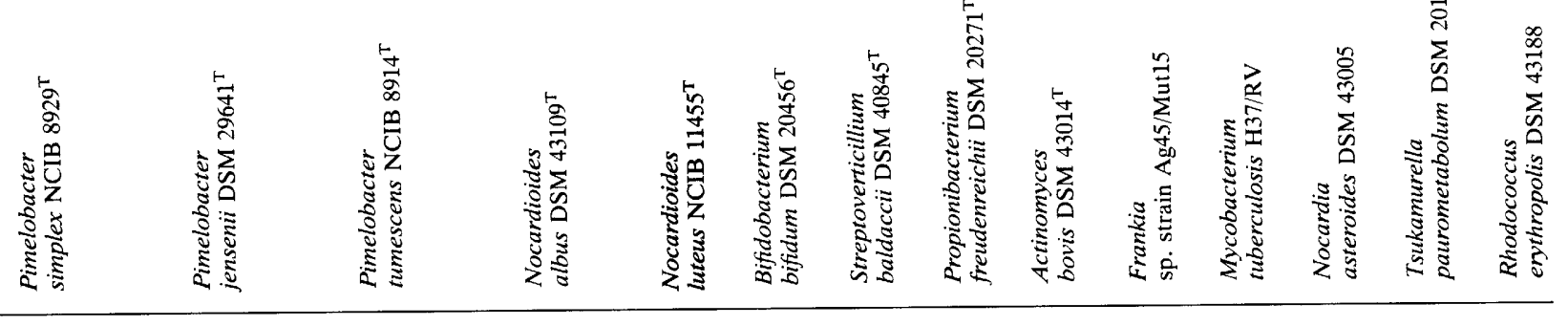

\begin{tabular}{|c|c|c|c|c|c|c|c|c|c|c|c|c|c|c|}
\hline Pimelobacter jensenii DSM $29641^{\mathrm{T}}$ & $88.7(94.2)$ & & & & & & & & & & & & & \\
\hline Pimelobacter tumescens NCIB $8914^{\mathrm{T}}$ & $81.4(90.6)$ & $82.4(91.8)$ & & & & & & & & & & & & \\
\hline Nocardioides albus DSM $43109^{\mathrm{T}}$ & $89.6(94.4)$ & $90.7(94.5)$ & $80.2(89.9)$ & & & & & & & & & & & \\
\hline Nocardioides luteus NCIB $11455^{\mathrm{T}}$ & $90.0(94.5)$ & $89.2(94.8)$ & $80.1(90.6)$ & $98.1(98.5)$ & & & & & & & & & & \\
\hline Bifidobacterium bifidum DSM $20456^{\mathrm{T}}$ & 62.2 & 64.7 & 65.2 & 63.8 & 63.4 & & & & & & & & & \\
\hline Streptoverticillium baldaccii DSM $40845^{\mathrm{T}}$ & 73.6 & 77.0 & 77.4 & 74.5 & 75.0 & 63.0 & & & & & & & & \\
\hline Propionibacterium freudenreichii DSM $20271^{\mathrm{T}}$ & 78.8 & 74.6 & 75.4 & 73.5 & 76.3 & 63.1 & 71.3 & & & & & & & \\
\hline Actinomyces bovis DSM $43014^{\mathrm{T}}$ & 71.5 & 69.1 & 74.5 & 68.2 & 70.3 & 67.7 & 69.7 & 69.0 & & & & & & \\
\hline Frankia sp. strain Ag45/Mut15 & 76.6 & 76.6 & 77.6 & 74.2 & 75.5 & 59.0 & 74.3 & 70.7 & 69.0 & & & & & \\
\hline Mycobacterium tuberculosis $\mathrm{H} 37 / \mathrm{RV}$ & 78.2 & 77.0 & 77.0 & 74.2 & 75.7 & 62.2 & 71.4 & 75.8 & 72.4 & 73.6 & & & & \\
\hline Nocardia asteroides DSM 43005 & 76.8 & 77.8 & 78.0 & 76.2 & 77.1 & 62.3 & 75.0 & 73.5 & 70.1 & 76.9 & 81.6 & & & \\
\hline Tsukamurella paurometabolum DSM $20162^{\mathrm{T}}$ & 79.6 & 76.7 & 80.8 & 75.5 & 76.8 & 63.5 & 75.4 & 76.7 & 73.8 & 77.0 & 83.5 & 84.0 & & \\
\hline Rhodococcus erythropolis DSM 43188 & 80.1 & 79.4 & 80.0 & 78.7 & 79.8 & 63.9 & 76.2 & 76.3 & 72.3 & 78.3 & 82.3 & 88.0 & 87.7 & \\
\hline Saccharomonospora viridis ATCC $15386^{\mathrm{T}}$ & 74.7 & 73.0 & 71.9 & 72.3 & 70.9 & 59.0 & 71.4 & 70.8 & 69.9 & 71.9 & 77.4 & 77.1 & 77.3 & 78.7 \\
\hline
\end{tabular}

a ATCC American Type Culture Collection; DSM, Deutsche Sammlung von Mikroorganismen; NCIB, National Collection of Industrial Bacteria.

ATCC, American Type Culture Collection; DSM, Deutsche Sammlung von Mikroorganismen; NCIB, National Collection of Industrial Bacteria.
The values in parentheses for Nocardioides and Pimelobacter species were based on a comparison of 1,449 nucleotides. The values not in parentheses were calculated from 480 nucleotides. 
glycolipids. The major isoprenoid quinones are tetrahydrogenated menaquinones with eight isoprene units [MK-8 (II,III- $\mathrm{H}_{4}$ )]. The guanine-plus-cytosine content of the deoxyribonucleic acid is 69.8 to 73.4 mol\% (thermal denaturation method). Phylogenetically, Terrabacter belongs to the actinomycetes subdivision, forming together with Nocardioides a separate line of descent. The type species is Terrabacter tumescens.

Description of Terrabacter tumescens (Jensen) comb. nov. The description below is based on data from references 3,8 , 10 , and 17. In addition to the characteristics of the genus, the salient characteristics are given below. A rod-coccus cycle occurs during growth on complex media. Cells from older cultures are coccoid (diameter, 0.5 to $0.8 \mu \mathrm{m}$ ). After transfer to fresh complex media long, irregular rods $(0.6$ to 1.2 by 2.0 to $6.0 \mu \mathrm{m}$ ) are formed. The long rods show primary branching. Aerial mycelium is not formed. Generally nonmotile (occasionally motile strains occur). Colonies are glossy, entire, smooth, and gray or white. Growth at 10 and $35^{\circ} \mathrm{C}$; may or may not grow at $37^{\circ} \mathrm{C}$. Optimum temperature for growth ca. 25 to $30^{\circ} \mathrm{C}$. Most strains grow in $5 \% \mathrm{NaCl}$. Obligately aerobic. Acid is not formed from glucose and other sugars in peptone-based media. Thiamine is the only growth factor required (when thiamine is provided, the organism utilizes an ammonium salt or nitrate as the sole nitrogen source in mineral salts medium with glucose as the carbon-plus-energy source). A wide range of organic compounds is utilized as sole or principal carbon-plus-energy sources for growth, including acetate, D-alanine, crotonate, inositol, $\alpha$-D-glucosamine, D-mannose, and raffinose; Dglucuronate, L-ornithine, D-phenylalanine, and uric acid are not utilized. Gelatin, hippurate, and tyrosine are hydrolyzed. Starch may or may not be hydrolyzed. Some strains hydrolyze Tween 80 . Deoxyribonuclease is produced. Urease and sulfatase negative. Some strains produce $\mathrm{H}_{2} \mathrm{~S}$. The guanineplus-cytosine content of the deoxyribonucleic acid is 69.8 to $72.4 \mathrm{~mol} \%$ (thermal denaturation method). Occurs in soil.

The type strain is strain NCIB 8914 (= DSM $20308=$ ATCC 6947). In most respects the description of the type strain corresponds to that of the species. The type strain is nonmotile. Starch and Tween 80 are hydrolyzed. $\mathrm{H}_{2} \mathrm{~S}$ is not produced.

\section{ACKNOWLEDGMENTS}

E.S. was supported by the Gesellschaft für Biotechnologische Forschung for performing research of relevance for the Deutsche Sammlung von Mikroorganismen, Braunschweig, Federal Republic of Germany. M.D.C. is grateful to the Agricultural Food Research Council, Institute of Food Research, Reading, United Kingdom, for support of the visit to the laboratory of E.S.

\section{LITERATURE CITED}

1. Brosius, J., J. L. Palmer, J. P. Kennedy, and H. F. Noller. 1978. Complete nucleotide sequence of a $16 \mathrm{~S}$ ribosomal RNA gene from Escherichia coli. Proc. Natl. Acad. Sci. USA 75:48014805 .

2. Charfreitag, D., M. D. Collins, and E. Stackebrandt. 1988. Reclassification of Arachnia propionica as Propionibacterium propionicus comb. nov. Int. J. Syst. Bacteriol. 38:354-357.

3. Collins, M. D., R. M. Keddie, and E. Kroppenstedt. 1983. Lipid composition of Arthrobacter simplex, Arthrobacter tumescens and possibly related taxa. Syst. Appl. Microbiol. 4:18-26.

4. Collins, M. D., J. Smida, M. Dorsch, and E. Stackebrandt. 1988. Tsukamurella gen. nov. harboring Corynebacterium paurometabolum and Rhodococcus aurantiacus. Int. J. Syst. Bacteriol. 38:385-391.

5. Cummins, C. S., and H. Harris. 1959. Taxonomic position of Arthrobacter. Nature (London) 184:831-832.

6. De Borde, D. C., C. W. Neave, M. L. Herlocher, and H. F. Maassab. 1986. Resolution of a common sequencing ambiguity by terminal deoxynucleotidyl transferase. Anal. Biochem. 157: 275-282.

7. Embley, T. M., J. Smida, and E. Stackebrandt. 1988. Reverse transcriptase sequencing of $16 \mathrm{~S}$ ribosomal RNA from Faenia rectivirgula, Pseudonocardia thermophila and Saccharopolyspora hirsuta, three wall type IV organisms which lack mycolic acids. J. Gen. Microbiol. 134:961-966.

8. Fitch, W. M., and E. Margoliash. 1967. Construction of phylogenetic trees: a method based on mutation distances as estimated from cytochrome $c$ sequences is of general applicability. Science 155:279-284.

9. Hori, H., and S. Osawa. 1979. Evolutionary change in 5S rRNA secondary structure and phylogenetic tree of 54 5S rRNA species. Proc. Natl. Acad. Sci. USA 76:381-385.

10. Keddie, R. M., M. D. Collins, and D. Jones. 1986. Genus Arthrobacter Conn and Dimmick 1947, p. 1288-1301. In P. H. A. Sneath, N. S. Mair, M. E. Sharpe, and J. G. Holt (ed.), Bergey's manual of systematic bacteriology, vol. 2. The Williams \& Wilkins Co., Baltimore.

11. Lane, D. J., B. Pace, G. J. Olsen, D. A. Stahl, M. L. Sogin, and N. R. Pace. 1985 . Rapid determination of 16 S ribosomal RNA sequences for phylogenetic analyses. Proc. Natl. Acad. Sci. USA 82:6955-6959.

12. O'Donnell, A. G., M. Goodfellow, and D. E. Minnikin. 1982. Lipids in the classification of Nocardioides: reclassification of Arthrobacter simplex (Jensen) Lochhead in the genus Nocardioides (Prauser) emend. O'Donnell et al. as Nocardioides simplex comb. nov. Arch. Microbiol. 133:323-329.

13. Prauser, H. 1976. Nocardioides, a new genus of the order Actinomycetales. Int. J. Syst. Bacteriol. 26:58-65.

14. Prauser, H. 1986. Genus Nocardioides Prauser 1976, p. 14811485. In P. H. A. Sneath, N. S. Mair, M. E. Sharpe, and J. G. Holt (ed.), Bergey's manual of systematic bacteriology, vol. 2. The Williams \& Wilkins Co., Baltimore.

15. Queen, C., and L. J. Korn. 1984. A comprehensive sequence analysis program for the IBM personal computer. Nucleic Acids Res. 12:581-599.

16. Schleifer, K. H., and O. Kandler. 1972. Peptidoglycan types of bacterial cell walls and their taxonomic implications. Bacteriol. Rev. 36:407-477.

17. Stackebrandt, E., and C. R. Woese. 1981. Towards a phylogeny of actinomyetes and related organisms. Curr. Microbiol. 5:197202.

18. Stackebrandt, E., and C. R. Woese. 1981. The evolution of prokaryotes, p. 1-31. In M. J. Carlile, J. F. Collins, and B. E. B. Moseley (ed.), Molecular and cellular aspects of microbial evolution. Cambridge University Press, Cambridge.

19. Suzuki, K., and K. Komagata. 1983. Pimelobacter gen. nov., a new genus of coryneform bacteria with LL-diaminopimelic acid in the cell wall. J. Gen. Appl. Microbiol. 29:59-71.

20. Yano, I., Y. Furukawa, and M. Kusunose. 1971. Fatty acid composition of Arthrobacter simplex grown on hydrocarbons: occurrence of 2-hydroxy-fatty acids. Eur. J. Biochem. 23:220228 .

21. Yano, I., Y. Furukawa, and M. Kusunose. 1971. 2-Hydroxy fatty acid containing phospholipid of Arthrobacter simplex. Biochim. Biophys. Acta 210:105-115. 